\title{
A investigação narrativa no âmbito da história oral de ações escolares de ensino e de aprendizagem
}

\author{
RosÁlia M. R. DE ARAGĀo \\ Doutora em Ciências Humanas, livre docente pela Unicamp e pró-reitora de Graduação e Ensino na Umesp
}

RESUMO

O estudo busca propiciar acesso à epistemologia da investigação narrativa compreendendo-a no âmbito da história oral de ações educativas cscolares. O texto é construído - em uma perspectiva da história da educação do presente - de forma tal que possa elucidar o que ocorre $\mathrm{cm}$ processos, eventos e rotinas escolares dos nossos dias.

Palavras-chave: Investigação narrativa. Memória de Processos Educativos. Histótias de Ensino

\section{ABSTRACT}

This article aims to contribute to the epistemology of the narrative inquiry, considering it from the point of view of the oral history and school education actions. The text was built -from a perspective of present education history-in such a way that it sheds some light on what occurs in the present days school processes routines and events.

Key words: Narrative inquiry. Memory of educative process. Teach history 
cm sido cada vez mais freqücnte o uso da investigação narrativa em estudos c pesquisas sobre a experiência humana. De forma tal que, podemos dizer, esta já tem uma longa história intelectual e académica dentro e fora da cducaçio. Dentre as razòes que explicam ou justificam, de forma mais convincente, o uso da narrativa na investigaçaio educativa, encontram-se as de CONNEILIY $\mathrm{e}$ CLANDININ (1995:11) quando ressaltam que "nós - os seres humanos - somos organismos contadores de histórias, organismos que, individual e socialmente, vivemos vidas relatadas". Sendo assim, para eles, o estudo da narrativa é o estudo da forma pela qual nós, os seres humanos, experimentamos o mundo. Fm outro àmbito, mas neste sentido, RIBEIRO (2000) afirma que "na vida não há fatos, o que há são histórias..."

É dessa idéia geral que decorre uma das proposiçōes atuais definidoras da educação como a 'construção e re-construçào de histórias pessoais c sociais'. Nesta perspectiva, tanto os professores como os alunos sào contadores de histórias c também personagens não só das histórias dos demais, mas das suas próprias histórias.

Nesse contexto, assumimos 'narrativa' como o termo de referencia a uma qualidade que estrutura a experiència que vai ser estudada e, além disso, como designativo dos padròes de investigação que vão ser utilizados para estudo dessa experiéncia. De modo geral, tendemos a chamar de 'história' ou 'relato' ao fenômeno, e de 'narrativa' à investigação e à feição final do texto dai resultante. Assim, quando dizemos que nós vivemos 'vidas relatadas' c contamos as histórias dessas vidas, precisamos dizer, para explicitar, que os pesquisadores que sào 'investigadores narrativos' buscam recolher 'essas vidas' - com base em memónias para, por sua vez, descrevè-las e contar histórias sobre elas, escrevendo seus relatos de uma tal experiência em uma 'narrativa'.

É justamente neste sentido que se estabelecem relaçòes várias no âmbito da História Oral como metodologia específica de investigaçāo.

A narrativa ocupa um lugar importante nas mais variadas disciplinas ou campos de saber, talvez porque 'narrar' seja inerente ao ser humano, isto ć, seja uma estrutura fundamental da experiência humana vivida. Talvez, por isso, apresente uma qualidade holística, uma vez que possibilita a todos nós "a expressão da nossa memória", isto é, "a expressào da 'história' do nosso ponto de vista, do lugar de onde podemos olhar c ver... não só com os olhos mas principalmente com a mente." (ARAGÃO, 1993:5)

Em decorrência de uma análise em nível macro, nessa perspectiva, CONNELLYY e CLANDININ (1995) definem três linhas de investigação, de caráter narrativo, relacionadas entre si, que incidem fundamentalmente sobre o 
relato, quais sejam : "a história oral, os contos das crianças e os usos de contos nas experiências lingüísticas", tanto na educação pré escolar quanto na eduçaçào escolar fundamental, média e superiot.

Dentre os estudos vários já desenvolvidos nessas vertentes, vale destacar uma versào curricular pouco conhecida ou menos divulgada dessa literatura, que inclui os trabalhos de EGAN (1986) e de JACKSON (1987), advinda da consideração de algguns outros elementos pedagógicos para admitir que "as matérias escolates estão geralmente organizadas na forma de historietas ou de contos." Nesse sentido, o último autor referido assinala que "mesmo quando a matéria em si não scja 'uma história', a lição - ou aula - contém usualmente um grande número de segmentos narrativos".

Além disso, de outro modo, Egan propôs um modelo que certamente nos estimula a que consideremos as aulas ou as unidades curriculares muito mais como boas histórias para serem contadas do que como conjuntos de objetivos a serem atingidos. Justamente no âmbito dessa concepção, ARAGÃO (C. Anais do II ENPEC, 1999) produziu sua comunicação sobre uma investigaçào narrativa da leitura, na disciplina curricular de Didática das Ciências - intitulada "É para ler, professora?" - quando tratou de telatar investigativamente episódios de leitura discente em sua própria prática docente.

O trabalho de Applebee (1978, apud CONNELLY c CLANDININ, 1995: 38), algumas vezes referido como 'o trabalho do grupo de Cambridge', incide sobre o "desenvolvimento do currículo" (para o ensino da linguagem) e sobre "métodos de ensino." De forma semelhante, desenvolve-se o próprio trabalho dos autores referidos sobre currículo, os quais entendem as narrativas idiossincráticas de professores como metáforas das relaçòes de ensinoaprendizagem. Isto porque, como eles próprios assinalam, "entendendo-nos, a nós mesmos e aos nossos alunos, de um ponto de vista educativo, necessitamos entender as pessoas que apresentam narrativas das suas experiências de vida." Mais ainda, em termos tais que se possa ressaltar a reciprocidade, posto que 'as narrativas de vida são o contexto no qual se dá sentido às situações escolares.' Neste âmbito, reitero que a narrativa está situada em uma matriz de investigação qualitativa, uma vez que sc funda na experiência vivida e nas qualidades da vida e da educação

Os autores por mim considerados e já citados referem-se, de forma destacada, à revisão de EISNER (1982) sobre 'o estudo educativo da experiência.' Isto porque este pesquisador relaciona a narrativa aos trabalhos de investigadores educacionais de orientaçào qualitativa que trabalham com a experiênctia em vírias areas do saber, tais como, filosofia, psicologia, teoria crítica, antropologia, bem 
como cstudos sobre currículos. Acrescentam, ainda, pela sua importância, a revisão procedida por ELBAZ (1983; 1988), relativa aos estudos sobre o pensamento do professor, por esta ter criado um perfil dos enfoques investigativos mais próximos da 'familia dos estudos narrativos'. A maneira como esta autora construiu tal 'família', implicou uma revisão acurada de estudos decorrentes de investigaçòes já desenvolvidas sobre 'o que é pessaal', em âmbito pedagógico, para evidenciar como tais estudos tinham/têm afinidade com a narrativa.

Uma outra questão importante para Elbaz teferida é relativa ao tema da 'voz', contudo, a sua principal preocupação é atinente ao 'relato', distinguindo-o não só como "um dispositivo metodológico", mas também como uma "metodologia em $\mathrm{si}^{i}$, ao tempo em que articula a narrativa com inúmeros estudos de educação, os quais - ainda que os seus autores não estejam conscientes de utilizar procedimentos narrativos - apresentam ou transmitem os seus dados $\mathrm{em}$ forma de relatos, ou utilizam documentos de histórias participativas como dados efetivos. Nessa visão, podem ser mencionados como trabalhos que estào relacionados com a narrativa, as investigaçōes de SHULMAN sobre 'professores especialistas' (1987), os trabalhos de SCHÖN sobre 'a prática reflexiva' (1987), os de MUNBY sobre 'as metáforas dos professores'(1986) e mesmo o de WILLIS (1990) sobrc 'processos de aprendizagem da cultura contra-escolar de trabalhadores', dentre outros.

Além disso, registra-se na literatura pertinente uma grande quantidade de estudos sobre educação que têm qualidades narrativas e que são chamados de relatos de professores e de rlatos sobre professores, em referencia ao telato ser de primeira ou de segunda mão, escritos por professores ou por outras pessoas, mas que, seguramente, tratam de aspectos relacionados a professores, alunos, aulas e... escolas! Dentre esses, merece destaque, ao meu ver, o trabalho intitulado A Vida nas Aular, de JACKSON (1968), já referido, que tem um papel pioneiro e, sem dúvida, sobremaneira significativo no que concerne à literatura do gêneto.

Várias possibilidades de investigaçào $\mathrm{em}$ uma perspectiva nartativa nos estudos sobre educação serào por mim consideradas, em função das minhas experiências quer como orientadora de trabalhos/pesquisas narrativos, em nível de pós-graduação, quer como pesquisadora-narrativa $\mathrm{cm}$ açào, no curso de minha própria prática pedagógica.

\section{Processos de inVestigaçño narrattva: \\ Eprsódio I}

- Uma experiência pessoal minha, em nível universitário, como 'professora de Didática das Cièncias', possibilita ilustrar um tipo de coleta de dados advinda 
da minha prática docente usual, quotidiana. É interessante observar, desde o início, que esta, bem como as várias modalidades de 'coleta de dados' - na ou para uma narrativa - geralmente ć (são) passivel(is) de combinação e de articulação com outras modalidades. Neste caso, as minhas anotaçōes de/cm 'diário de campo' desta experiência, relativa à bistória de minha práfica ussual de ensino, se deram em concomitância com gravaçồes cm 'áudio' de cada uma das aulas por mim ministradas para a turma de alunos sob enfoque. Sendo assim, as anotações em pauta passam a estar muito mais restritas a aspectos não passiveis de verbalização, ou de registro pelo gravador, que dizem respeito, geralmente, à observação do clima de sala de aula, de expressòes corporais ou faciais dos alunos, a anotaçòes da lousa ou de cadernos dos alunos, à interação sinalizada entre eles, à conduta de grupos localizados, a entonaçòes expressas com refotço 'mímico' do professor ou dos próprios alunos, a pensamentos e sentimentos docentes no curso do processo de ensino e de aprendizagem, dentre outras. Vejamos algumas das minhas notaçōes nesse âmbito:

... Meus alunos sempre parecem extremamente surpresos quando eu uso qualquer expressão de pouca consideração - e mesmo de subestimação - de 'regras meramente burocráticas ou técnicas' que estäo, geralmente, relacionadas ao poder docente no ensino tal como ocorre em sala de aula. Alguns se entreolham arregalando os olhos, ou com trejeitos de boca e de expressào fisionómica, denotando dificuldade de compreensão ou grande estranheza... Foi o que aconteceu quando eu lhes disse que eles deveriam me entregar o trabalho que estava sendo proposto, no tempo estimado por eles mesmos; eles que decidissem a data de entrega $\mathrm{cm}$ função da situação de cada um, para que eu pudesse assegurar certas condiçòes para uma realização tranqüila, sem corre-corre... Contudo, eu precisava ter idéia do 'prazo mínimo' possível do seu (deles) ponto de vista, e do 'prazo máximo', para cu me organizar, uma vez que eu precisaria de - pelo menos três dias para leitura, antes da data cstipulada para a entrega de notas ao serviço de controle acadêmico... e nào gostaria de atrasar. A surpresa foi tanta, que cles terminaram por me dizer o quanto é/cra 'incrivel', para eles, ver como uma professora 'doutora' pode 'abrir mào' de sua conveniência, e até de sua autoridade, $\mathrm{cm}$ beneficio dos scus alunos... Não pareciam se convencer da minha argumentação quando eu retruquei que não estava, no caso, 'abrindo mào de nada', permanecia com a minha 
conveniência e com a minha autotidade docente nos mesmos termos em que eu sempre busquei mantê-las...nos termos em que estas sempre se mantiveram...A diferença de minha atitude para as atitudes docentes usuais, é que eu utilizava 'critérios pedagógicos', isto é, os meus critérios eram intencionalmente pedagógicos por poder fazê-los crescerem apenas por tomar conhecimento deles como norteadores de suas açòcs e deles efetivamente partilharem... Declarei não acreditar que eles não entendessem que "nós estávamos do mesmo lado $\mathrm{e}$ nào $\mathrm{em}$ lados antagônicos ou diferentes... que a nossa interação possibilitava uma construção cognitiva corjunta, colabotativa..." (Notas de meu 'Diário de Campo' de set. /1997)

\section{EPIsódio II}

- Na investigação da minha prática pedagógica por uma outra professora em situação semelhante à relatada anteriormente, mas com outra turma de alunos - as anotaçòes por ela procedidas nesta modalidade foram articuladas com 'entrevistas' realizadas comigo, enquanto professora, logo após o término da aula ou, no mais tardar, no dia seguinte, para nào perdermos a "calor do episódio" destacado pela professota referida nas anotaçōes do seu diário de campo - que eram também relativas a questões pedagógicas e até mesmo a 'curiosidades pedagógicas investigativas' tais como "por que você fez ou disse isso ou aquilo..." (CARNINT'TO,1999) Daí, advém uma relação com a prática pedagógica observada - cerne da narrativa encetada pela professora-autora referida - registrada nas suas 'anotaçòes cm diário de campo das minhas aulas'. Por tratar-se de minha prática de ensino intencionalmente redimensionada naquele momento, em termos tais que gerava diferenciaçào contundente do ensino usual caracteristicamente autoritário, a 'confusào', que se estabelecia para o observador, era desde o início relativa ao que consistia em uma nova/outra 'prítica de ensino interativo' tendo em vista a construção do conhecimento pelos alunos.

Algumas anotaçōes do diário de campo de CARNIATTO (1999:17) registram seus pensamentos $\mathrm{cm}$ termos como os seguintes:

... Neste dia, reiniciar-se-ão as aulas da disciplina de Didática Geral, que a Professora, segundo disse, abordarí como Didática das Ciências/Biologia. O que eles [os alunos] esperam de uma disciplina dessa natureza? Muito provavelmente, tal relaçăo $\mathrm{cm}$ nada vai mudar a credibilidade inicial da Didática para a turma. ... A propósito de proposiçòes provocativas de alunos, dirigidas 
de modo geral à classe, mas que, certamente, tinha como objetivo provocar a Professora - que estava entrando na sala de aula acompanhada de duas monitoras - destaco a fala de um aluno que, logo à entrada da Professora na sala de aula, disse alto para que todos o ouvissem, marcando o ritmo da observação pretensamente em rima: "Graças a Deus... eu sempre dissc... que didática não existe!" (...) De forma clara, manifestando, talvez, comprecnsào, em funçăo de reflexỏes como essas que, certamente, já fizera, em resposta ao aluno a Professora concorda que "na maior parte das situaçóes de ensino, a didática não existe; ele [o aluno] tem plena razào." [E a provocaçào se tornou o "tema da aula' na perspectiva descjada de ensino interativo... de forma altamente motivadora para todos].

\section{EpIsódio III}

- Um outto instrumento de coleta de dados usado com grande freqüência na investigação narrativa é a entrersista em qualquer das seguintes feiçòes: estruturada, 'não' ou 'semi' estruturada. As entrevistas - que constituem este terceiro Episódio que desejo enfocar - sào realizadas pelo investigador com os sujeitos participantes da pesquisa, $e$ gravadas pelo menos em 'áudio'. As falas das gravações são transcritas e, em função destas, outros/novos encontros sảo preparados para facilitar a discussào subseqüente. Ao final, as entrevistas escritas e recscritas se convertem cm 'documentos' imprescindíveis a investigação no curso da narrativa. Nestes termos, há exemplos de entrevistas, que são passiveis de destaque, em processos de investigaçio natrativa. GONCCALVES (2000:35), por exemplo, adotou como instrumento efetivo de coleta de dados as 'entrevistas não estruturadas' para possibilitar estabelecer as múltiplas relações que certamente a sua nartativa exigiria por tratar da reconstituiçào de histótias vividas/compartilhadas por cla com os participantes da pesquisa, tendo em vista objetivos de pesquisa. Escreveu a autora que a sua

"abordagem metodológica de pesquisa parece possibilitar estabelecer as múltiplas relaçōes que, certamente, o estudo cstá a exigir, dando voz aos atores daquele processo em análise, reconstituindo com ela [enquanto pesquisadora] histórias decorrentes da vida daqueles professores, que são personagens da histótia do ensino e da formação de professores de Ciências no seu Estado natal..."

Os entrevistados - no àmbito dessa investigaçào narrativa - participaram dessa história de modos diferentes, conforme o seu tempo de formados, a sua história de vida... Cada um a seu modo vibra com o que construiu... Alguns se 
sentindo, provavelmente, mais ou menos autores do que outros...

...Os professores entrevistados e eu participamos de uma experiéncia comum... Portanto, tanto eles quanto eu, como pesquisadora, temos voz na pesquisa. Como sói acontecer na pesquisa qualitativa $\mathrm{cm}$ geral, a relação sujeito-objeto nâo ć neutra. O pesquisador busca conhecer, porque tem objetivos previamente definidos e o entrevistado decide participar porque tem alguma motivação para isso. Mas aqui, a voz do pesquisador não procura ser a que categoriza, a que molda, mas a que organiza, cxpõe, interpreta, discute, buscando contrapontos à prática efetivada e evidenciada nas vozes dos participantes, em literaturas várias sobre práticas similares e sobre princípios teóricos que as sustentam.

CHAVES (2000) explicita, de outra forma, esse mesmo propósito quando diz, em vários excertos:

“... a narração harmoniza-se duplamente: com minha intenção de contar, relatar o experienciado, e com o mcu propósito de elucidar percursos e percalços que constituem a trajetória de processos de investigação (...) Propósito ... ao qual o potencial educativo do texto narrativo $\mathrm{vem} s \mathrm{se}$ coadunar, uma vez que 'as histórias funcionam como argumentos com os quais aprendemos algo essencialmente humano comprecndendo uma vida concreta ou uma comunidade particular tal como são vividas'... São momentos relatados da 'vida'/experiência 'concreta' de nossa 'comunidade'/grupo de formadores, no curso de formação de professores de ciências sob análise, que constituem as fontes de onde obtive o material empírico a partir do qual construí os 'dados' que figuram nesta tese(...) Assim, as vozes dos sujeitos, que construitam o processo de formaçào de professores que vivenciei $\mathrm{c}$ do qual fui igualmente artifice, foram obtidas basicamente nas 'reuniòes' de planejamento e avaliaģão das alividades desenvolvidas pelo grupo de formadores, em 'entrevistas' com membros do grupo de formadores, em 'materiais' (rolitros e projetos) produzidos pelo grupo de formadores e em 'notas de campo' que produzi durante o processo de formação investigado". (Os grifos são meus)

Uma das questōes preliminares que se põe em relação à investigação nartativa como processo é 'como se toma a decisào de envolvimento em uma situaçào de 
campo', no confronto mesmo com a pesquisa em educação. Isto já manifesta, de início, que tal situação não implica uma simples questão de escolha, de uma mera opçào por preferência pessoal ou acadêmica, mas essa tomada de decisão é vista como uma questão éliza que tem a ver com os princípios que estejam envolvidos tanto nas responsabilidades dos investigadores quanto dos sujeitos participantes da investigação. Em termos mais especificos, o processo de tomada de decisão é um tipo de 'negociação de entrada no campo de pesquisa' e, por isso mesmo, é visto como uma discussào preliminar sobre uma unidade narrativa compartilhada, uma unidade narrativa interativa. CLANDININ e CONNEILY (1988: 281) expressam seu ponto de vista a esse respeito nos seguintes termos:

"Pudemos demonstrar que ter êxito na negociaçào c na aplicação de princípios [comuns] não gatantem por si sós um estudo frutífero. A razào, naturalmente, é que a investigaçào colaborativa constitui uma relação. Na vida quotidiana, por exemplo, a idéia de amizade implica a existência de algo que é compartilhado: a interpretação de duas ou mais esferas pessoais de experiencias. Um mero contacto é [apenas] reconhecimento, não amizade. $\mathrm{O}$ mesmo se pode dizer da investigação colaborativa enquanto requer uma relaçào intensa, análoga à amizade. Assim, 'as relaçòes se estabelecem', como assinala MacIntyre (1981), 'através das unidades narrativas de nossas vidas'."'

Enfatizam, dessa forma, esses autores, que a 'opçào' pela investigaçào narrativa transcorre/ocorre no âmbito de uma telação entre os investigadores e os sujeitos da investigação, construída como uma 'unidade de atençào mutuamente inclusiva cm âmbito comunitário' (designada pela expressào inglesa 'carning comunity'). Além disso, assinalam com NODDINGS (1986) que - "como na investigação sobre ensino se presta muito pouca atençào, na atualidade, aos assuntos referentes à comunidade e à 'colcgialidade' - essa investigação [colabotativa/narrativa] deveria ser interpretada e construída como uma investigaçào para o ensino," "uma investigação do ensino'. Isto porque se enfatiza, continuadamente, a natureza colabotativa do processo de investigação, considerando que todos os participantes se vêem como membros de uma comunidade que tem valor para eles próprios investigadores e sujcitos da investigação - para a teoria e para a prática, como pode ocorrer $\mathrm{em}$ situações de ensino, em aulas.

Ainda nesse sentido, vários dos autores ora enfocados destacam a contribuiçào de HOGAN (1988), quando este se pronuncia sobre as relaçōes na investigaçao narrativa, de forma similar, ao dizer que 
"as relaçòes [interativas] nas quais se aprimoram ou se fortalecem as próprias disposiçōes e capacidades (referidas como 'cmpowering relationships') [geralmente] se desenvolvem com o tempo; e [é preciso assinalat] leva tempo para os participantes reconhecerem o valor que subjaz a essas relaçōes. Tais relaçòes implicam sentimentos de articulaçào que se desenvolvem em situaçòes de igualdade, atenção mútua, bem como de propósitos c intenções compartilhados."

Assim, são destacados os elementos considerados relevantes na relação de investigação: 'a igualdade entre os participantes, a situação de atenção mútua e os sentimentos de envolvimento, de associação'. Dentre estes, ao meu ver, um certo sentido de igualdade entre os participantes é particularmente importante na investigação narrativa. Contudo, o(s) sujeito(s) da investigaçio - que durante muito tempo foi(ram) mantido(s) em silencio como reles 'objeto(s) de cstudo' - ou mesmo o próprio investigador - pode(m) não se ver com voz própria no processo de investigaçio e, dessa forma, muitas vezes, scntir-se desanimado(s) e desautorizado(s) a contar sua(s) história(s) por, de alguma forma, passar(em) a se sentir desigual(is), inferior(es).

Vale reiterar que se destaca efetivamente a necessidade de 'tempo', de 'relação', de 'espaço' e de 'voz', quando se estabelece a 'relação de colaboração', uma relação na qual tanto o investigador quanto os sujeitos participantes 'têm VOZ', no sentido que BRI'ZMAN (citado por CONNELLY e CLANDININ, 1995: 20) aponta, qual seja: 'a voz'

"ć o sentido que reside no individuo e que the permite participar de uma comunidade...A luta pela voz começa quando uma pessoa tenta comunicar sentido a alguém. Parte desse processo inclui encontrar as palavras, falar por si mesmo e sentir-se ouvido por outros... A voz sugere relaçōes: (1) a rclação do individuo com o sentido de sua experiência ( $\mathrm{c}$ portanto com a linguagem), $\mathrm{c}(2)$ a relação do individuo como outro, já que a compreensão é um processo social." (Traduçio livre de minha autoria)

Por tudo isso, ao começarmos um processo de investigação narrativa, tornase particularmente importante que todos os participantes tenham voz dentro da relação colaborativa. Para que isso possa efetivar-se, é preciso, como assinala EL_BOW (1986), que se assuma um 'jogo de crenga', quer dizer, é preciso supor uma forma de 
trabalhar no interior de uma relaçào que exige conhecimento articulado, de uma relaçào na qual 'aquele que conhece está pessoalmente unido ao conhecido'. Nestes termos, torna-se imprescindivel tessaltar que o 'jogo de crenfa' implica uma forma de conhecimento que se centra em um processo de auto-inserção na história do outro como uma forma de conhecer essa história e, ao mesmo tempo, como uma maneira de 'dar wo a a outro'. ELBOW acentua a natureza colaborativa desse "jogo" quando explicita que $o$ "'jogo de crença'... é essencialmente cooperativo ou participativo. Seu acontecimento central é o ato de alguém poder entrar no pensamento ou na percepção de um outro... alguém."

Podemos, em funçào das considerações tecidas até agota, afirmar que 'a investigaçào narrativa é deflagrada pela história do outro', na forma incidente à bistória oral. Isto quer dizer que è fundamental que o investigador escute primeiro a

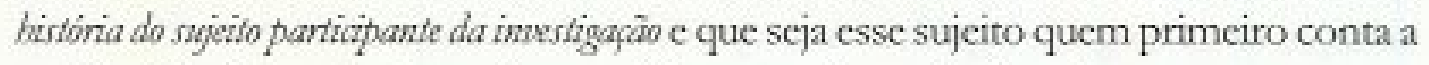
sua história. Contudo, isto nào quer dizer que o investigador deva permanecer $\mathrm{cm}$ siléncio durante o processo de investigação... Quer dizer que se dá o tempo e se abre o espaço necessários para que aquele - que permaneccu mais tempo em silêncio ou jamais teve voz - possa contar a sua história de forma tal que esta venha assumir a 'autoridade do dizer' c a 'validade de verossimilhança' que geralmente os relatos de pesquisa buscam apresentar.

\section{O PROCESSO DE INVESTIGAÇÃO NARRATIVA: ALGUUNS ASPECTOS VIVENCIAIS}

Assumirmo-nos como investigadores narrativos e sermos capazes de ver e de descrever relatos - histórias - das açōes diárias de professores, de alunos e de administradores escolares, dentre outros, requer habilidade mental em termos de certa 'versatilidade para olhar (e ver)', como também 'para dizer', por parte de quem investiga. À medida que se intensifica a tecitura, ou a 'trama', por que se vão contando e recontando histórias, nesse processo, sào estabelecidos, se ajustam e reajustam, os aspectos vários, temporair, soctais $\mathrm{e}$ culturais.

Por aspectos como esses, que sào ressaltados é que posso afirmar que tornamonos investigadores natrativos mais eficientes quando buscamos narrar estruturando, sistematizando - as histórias da nossa prática pedagógica, das nossas interaçōes docentes que são partilhadas com os alunos, os episódios de nossas aulas, implicando nós próptios e os alunos e/ou os alunos entre si, nuances e matizes do conteúdo/conhecimento que está/estava sendo tratado nas interaçōes, bem como confrontos interessantes de pré-concepçòes individuais em relação a conceitos científicos estabelecidos. Por isso, 'os professores-pesquisadores, ao meu ver, são sobretudo investigadores narrativos.' 
Em minha experiência pessoal, estruturo histórias várias, ao buscar narrar açōes partilhadas de "aulas de Didática", por exemplo, no processo da formaçio inicial de professores das Cièncias Tais ações, no curso da narrativa, assumem algurnas vezes conotaçōes maièuticas (dialógicas), sobtemancira interessantes. Nesses casos, como posso concluir, torna-se imprescindível a 'voz do aluno' nas várias interaçòes pata que cu possa - enquanto investigadora narrativa - constituir e lidar com a 'históna do ponto de vista do aluno', do seu pensamento, dos seus procedimentos, de suas atitudes.

Nas áreas teórico-práticas da educaçào - e em outras das ciências sociais - a investigação narrativa é urna forma de 'narrativa cmpirica', em que os dados empiricos são centrais para o trabalho investigativa. Mesmo assim, parece inevitável que a interpretacão se torne 'intrinseca' ao processo de coleta de dados. Contudo, tal situação se dá longe de significar uma aproximação indesejável da narrativa de um plano de ficçio, ainda que a linguagem da nartativa possa assumir um nivel de tequinte e de sofisticação lingüisticos que expresse cettos 'matizes' considerados literários ou poéticos, contudo ditos sobremaneira desejáveis ou mesmo imprescindiveis.

Ėm situaçōes de orientação metodológica de pesquisa em cducaçio, costumo dizer aos pós-graduandos, meus alunos, que visam formar-se em pesquisa, que um dos tequisitos pessoais para se poder ser um 'bom' investigador narrativo em educaçào implica, sem dúvida, 'domínio cfetivo de linguagem(ns) em termos especialmente da elaboração diferenciada, ou mesmo requintada, das palavras em construçōes lingüisticas as mais eloquientes, as mais expressivas para o caso ou telato que está sendo tratado'

Por outro lado, vários 'procedimentos de coleta de dados' são passiveis de adoção conjunta, nesta abordagem de pesquisa, posto que o investigador e o sujeito da investigaçĩo trabalham juntos $\mathrm{cm}$ uma telação de colaboraçào, já referida. Os dados podem ser coletados, por exemplo, em forma de anotaçōes em um 'diário de campo' da experiência partilhada, ou de 'notas pessoais', de 'transcriçōes de entrevistas', de 'observaçòes' de outras pessoas, de 'escritos autobiográficos, bem como de outras e várias açòes, tais como, 'escrever cartas, contar casos...'

Além disso, coletam-se dados também através de documentos diversos, dentre os quais, planos de ensino/de curso/de aula, boletins, atas ou quaisquer registros oficiais, tanto quanto de outros materiais escritos como regulamentos, regimentos, estatutos, normas. Tornam-se, ainda, dados preciosos, muitas vezes, a expressào de princípios, de imagens, de metáforas e de filosofas pessoais.

Enfim, na perspectiva de coleta de dados, bem como do tipo, da natureza e/ ou da qualidade dos dados, torna-se imprescindivel compreender a importância (1) da construgĩo do documento bistórico no qual se funda a narnativa e (2) 'da narrativa em 
termos de totalidade, em uma feiçio final.' Vale explicitar que fo sentido de totalidade é algo que se constrói' graças a uma fonte de dados rica, cuidadosamente elaborada como documento, de forma tal que possa enfocar particularidades e características da vida, a partir das quais se possam criar relatos ou histórias com a força de expressào desçável em qualquer investigação, mas especialmente na investigação em educaçào.

Precisamos ter presente, em qualquer caso, que a investigaçào narrativa é um processo de colaboraçào que incide sobre uma 'explic(it) ação e uma re-explic(it)açăo de histórias', mutuamente inclusivas, à medida que a investigação se desenvolve. No inicio de um processo compartilhado de investigaçào, o investigador precisa estat consciente desta 'partilha', isto é, de estar construindo uma relaçio cm que ambas as vozes (do investigador e do sujeito da investigação), ou as várias vozes (do investigador e dos sujeitos da investigação) possam ser ouvidas É isto que significa 'viver a história compartilhada' na investigação narrativa, na perspectiva de construção mútua da relaçào de investigação, 'uma relação em que tanto o investigador quanto o sujeito da investigaçào se sentem imbricados, ligados, associados pelos seus relatos e por suas vozes ao contarem suas histórias'.

Posso ressaltar, ao final, que a importância desta linha de pesquisa para a educação reside no que ela propicia por constituir-se $\mathrm{cm}$ um tipo de abordagem de idéias teóricas e teórico-práticas sobre a natureza da vida humana que pode ser usada na experiência educativa, enquanto experiência 'vivida' no âmbito da 'história oral como história do presente'.

Por essas razöes, considero pedagogicamente relevante dar a público tais contribuiçōes em uma perspectiva de 'explicitação para reflexào' de/sobre vários aspectos, nào só metodológicos mas, principalmente, epistemológicos da investigação narrativa histórica de açòes/processos cducativos escolares.

\section{BIBLIOGRAFIA}

ARAGÃO, R. M. R. de. 'Reflexões sobre ensino, aprendizagem, conhecimento...', in: Revista de Ciênita er Tecnologia. Piracicaba: Unimep, Ano 2, No 3, Julho/1993.

'É para ler professora? Investigando a leitura na didática das ciências', in: Anais do II ENPEC - Enontro National de Pexquisa en Eduaz̧ão en Gầniar. Valinhos: 1999. CARNIATTO, I. "A formação inicial do sujeito professor - Investigaçào narrativa na prática do ensino da didática das ciências/biologia". Dissertação de mestrado. Piracicaba: FE/Unimep, 1999.

CHAVES, S. N. "A construção coletiva de uma prática de formação de professores de ciências: tensòes entre o pensar e o agir." Tese de doutorado Campinas: FE/ Unicamp, 2000 . 
CLANDININ, F. M. \& CONNELLY, F. M. 'Studying teachers' knowledge of classrooms. Collaborative research, cthics and the negotiation of narrative', in: The Journal of Education Thought, 22, 269-282,1988.

CONNEILY, F. M. \& CI.ANDININ, D. J. 'Relatos de experiencia e investigación narrativa', in: LARROSA, J. et allii. DÉ] AME QUE TE CUENTE-Ensaos Sobre Narrativa y Edwación. Barcelona: Lacrtes, S. A. de Ediciones, 1995.

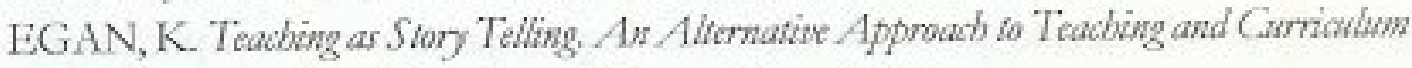
in the Elementary Sibooks. London: Althouse Press, 1986.

EISNER, E. W. Cognition and Gurrianlom. A Basis for Deciding what to Tead. New York: Longman, 1982

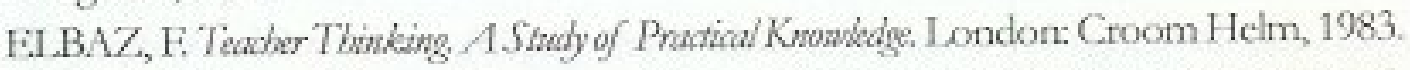

EILBAZ, F. Knowledge and discourse. The evolution of research on teacher thinking'. Paperapresentado na Conference of the International Study Association of Teacher Thinking. University of Nottingham, 1988.

ELBOW, P. Embraxing Contnaries Exphonations in Teathing and Leaning. Oxford: Oxford University Press, 1986.

GONCALVES, T. V. O. "Ensino de ciências e matemática c formação de professores: marcas da diferença". Tese de doutorado. Campinas: FE/Unicamp, 2000.

HOGAN, P. "A community of teachers researchers. A story of empowerment and voice" Manuscrito não publicado. University of Calgary, 1988.

JACKSON, P. W. "On the place of narmation on teaching", im: D. Berliner \& B. Rosenshine (eds.) Talks to teaders. New York: Random House, 1987.

JACKSON, P. W. Life in Classmoms. Chiacago: Holt, Hinchart \& Winston, 1968.

MUNBY, H. Metaphor in the thinking of teachers'. Journal of Ciorrizulum Studies, 18 , 197-209, 1986.

NODDINGS, N. 'Fidelity in teaching, teacher education, ando research for teaching' Harnand Eduational Rerriow, 56, 496-510, 1986.

RIBEIRO, J. U. Entrevista. Espaço Aberto-GloboNews, 2000.

SCHON, D. Educaling the Reflective Pratitioner. San Ftancisco: Jossey-Bass, 1987.

SCHULMAN, L. S. 'Knowledge and teaching. Foundations of the new reform'. Harnard Educational Revien, 57, 1-22, 1987.

WILIIS, P. Aprondendo a ser Trabalhador - Escola, Resistencia e Reproduçäs Sorial Porto Alegre: Artes Médicas, 1991. 